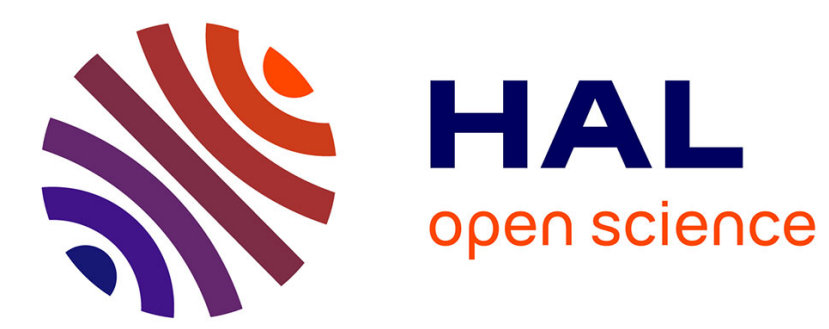

\title{
NEW METHODS OF STUDYING DISORDERED SOLIDS
}

\author{
J. Mackenzie, J. Lau
}

\section{To cite this version:}

J. Mackenzie, J. Lau. NEW METHODS OF STUDYING DISORDERED SOLIDS. Journal de Physique Colloques, 1982, 43 (C9), pp.C9-7-C9-16. 10.1051/jphyscol:1982902 . jpa-00222395

\section{HAL Id: jpa-00222395 https://hal.science/jpa-00222395}

Submitted on 1 Jan 1982

HAL is a multi-disciplinary open access archive for the deposit and dissemination of scientific research documents, whether they are published or not. The documents may come from teaching and research institutions in France or abroad, or from public or private research centers.
L'archive ouverte pluridisciplinaire HAL, est destinée au dépôt et à la diffusion de documents scientifiques de niveau recherche, publiés ou non, émanant des établissements d'enseignement et de recherche français ou étrangers, des laboratoires publics ou privés. 
JOURNAL DE PHYSIQUE

Colzoque C9, supplément au n², Tome 43, décembre 1982

page $\mathrm{c} 9-7$

NEW METHODS OF STUDYING DISORDERED SOLIDS

J.D. Mackenzie and J. Lau

Department of Materials Science and Engineering, University of California, Los Angeles, Califomia 900024 , U.S.A.

Résumé.- Pendant les cinq annëes écoulëes plusieurs nouvelles mëthodes ont été employées pour élucider les différents aspects de la structure des solides amorphes, tels que la structure locale, la structure à distance (long range), la microstructure et la structure de défauts. En même temps beaucoup de nouveaux solides amorphes ont été préparés et, pourtant, dans un certain sens le nombre des problèmes à rêsoudre n'a pas diminué. De plus, des nouveaux outils ont êtê employés pour arriver à la compréhension de certaines propriétés importantes des solides amorphes. En dëpit de plusieurs nouvelles techniques et tentatives il existe encore beaucoup d'incertitude regardant la structure aussi bien que les propriétés. Nous passons en revue certaines récentes contributions positives et discutons les difficultēs qui restent à surmonter.

Abstract. - In the past five years or so, many new methods have been used to elucidate the different aspects of the structure of disordered solids such as local structure, long-range structure, microstructure, and defect structure. Simultaneously, many new disordered solids have been prepared and hence the number of unsolved problems are in a sense undiminished. In addition, new tools have been utilized to gain understanding of some important properties of disordered solids. Despite the many new techniques and approaches, much remains uncertain both with respect to structure and to properties. The recent positive contributions of new methods are critically reviewed and some continuing challenges discussed.

1. Introduction. - In the past five years or so, a great deal of results of structural studies of disordered solids have been published. Many of the newer methods seemed to have played key roles in advancing our knowledge on structures. The main objective of this paper is to assess the contributions made by the use of these newer methods. Because of the enormously large amount of information available, both on the different types of disordered solids and on the different structural tools, this review must be restricted. Secondly, because detailed discussions on some methods and materials are already treated separately in this conference, for instance, metallic glasses, NRR, laser-induced fluorescence, glass surfaces and molecular-dynamic simulations, this review is selective with recard to topics. The major emphasis of this review will be placed on experimental results on oxide glasses. In critically reviewing the impact of the newer structural tools, three important questions were asked:

(a) What is the state of our knowledge prior to the "new" method or "new" study in question?

(b) What is the present state of our knowledge as a resuit of the "new" method or "new" study?

(c) What is sti11 uncertain, still controversial and stil1 unknown?

It is only by seeking answers to these questions that one can make critical conclusions regarding the status of our knowledge on glass structures and to be able to formulate plans for future productive research. 
2. Types of Structural Information. - The types of structural information available or desirable are listed in Table 1 together with the possible variations and uncertainties which must be considered. As an example of the complexities encountered

TABLE 1. Types of Structural Information and the Variables and Uncertainties

A. Types

1. Single phase or host material:

2. Minor constituents

3. Microstructure

\author{
Short range \\ Intermediate range \\ Long range \\ Mannetic \\ Dopants \\ Impurities \\ Defects
}

Liquid-7iquid

Liçuid-crysta 1

\section{B. Variables and Uncertainties for Each Type}

1. Concentration of the type

2. Distribution of the type

3. Effects due to preparation history

4. Effects due to variations during measurements

just with short range structural information alone, we can cite the case of binary alkali-germanates or alkaline earth-germanates (Ficure 1). When binary germanate

$$
\begin{aligned}
& x\left[\begin{array}{cc}
1 \\
0 \\
1 \\
-0-G e & -0 \\
1 \\
0
\end{array}\right]_{\infty}+(1-x) M_{2} 0 \\
& x\left[\begin{array}{cc}
1 \\
1 \\
-0-\underset{1}{1}- & -0 \\
0 \\
1
\end{array}\right]_{\infty}+(1-x) M 0
\end{aligned}
$$

1. Formation of $\left(\mathrm{GeO}_{6}\right)$ groups

2. Formation of non-bridaing oxygens

3. (1) and/or (2)

4. Number of non-bridging oxygens per Ge

5. Clustering of $\mathrm{M}^{+}$and $\mathrm{M}^{2+}$

Figure 1. Short-range structural information needed for binary germanates.

glasses are formed, we need to know if $\left(\mathrm{GeO}_{6}\right)$ groups are created, assuming a 11 the germaniums are four-coordinated to begin with. Then, there are possibilities of creation of non-bridging oxygen ions. Then we need to know if there are both $\left(\mathrm{GeO}_{6}\right)$ and non-bridging oxygens, their relative concentrations as a function of $\mathrm{x}$, 
the number of non-bridging oxygens per Ge and if the $\mathrm{Hi}^{+}$and $\mathrm{M}^{2+}$ ions are clustered. There are additional possibilities such as Ge-coordinations other than 4 and 6 , oxygen vacancies, etc. For each disordered solid having constant chemical composition, there are variables and uncertainties associated with the history of preparation. For instance, solids made by cooling off the melt could be different from those prepared from vapor condensation or from densification of solutionderived gels.

When one reviews the work on disordered solids in the past five years, the types of materials reported were indeed numerous. A convenient division into types is shown in Table 2 for inorganics only.

TABLE 2. Different Types of Disordered Inorganic Solids and Techniques of Preparation

A. Types

Oxides

Chalcogenides

Halides

Metals

\section{B. Techniques of Preparation}

Melt cooling

Heating of solution-derived gels

Precipitation from solutions

Condensation from vapor 0xynitrides

Oxychalcogenides

Oxyhatides

Covalent Elements

If the variations of chemical composition for each type are also considered, the total are even greater. A1though for many studies, the emphas is might have been on properties and not structure, most authors do discuss structure. A comprehensive critical analysis of all papers is certainly impossible.

A summary of some of the important "newer" methods employed in the past few years is shown in Table 3. The terms "new" or "newer" are of course relative and for the

TABLE 3. Some of the "Newer" Methods Used in Structural Studies of Disordered Solids in the Past Five Years

1. Electron spectroscopy (ultraviolet photoelectron spectroscopy, UPS; X-ray photoelectron spectroscopy, XPS) [1-4]

2. Extended X-ray absorption fine structure (EXAFS) [5-9]

3. High resolution electron microscopy (HREM) [10]

4. Laser-induced fluorescence line-narrowing (FLN) [11]

5. Magnetic resonance (NMR, ESR) [12-13]

6. Mössbauer spectroscopy [14-15]

7. Neutron scattering [16-17]

8. Raman spectroscopy [18-20]

9. Scanning transmission electron microscopy (STEM) [21-22]

10. Sma 71 angle X-ray scattering (SAXS) [23-24]

17. X-ray absorption near edge structure (XANES) [25]

12. X-ray diffraction [26-28]

13. Modeli ing [29-3i]

14. Inert gas permeation [32]

present paper, we have included "old" methods for which improvements in experimental and/or theoretical aspects have been made. When Tables 1, 2, and 3 are combined, the list for critical evaluation is practically endless. Thus only some specific examples are discussed below. 
3. Some Specific Examples. - (a) $\mathrm{GeO}_{2}$ and Germates: As early as 1934, B. E. Varren found that $\mathrm{GeO}_{2}$ glass was structuraliy similar to $\mathrm{SiO}_{2}$ glass in that Ge was tetrahedrally coordinated and the $\mathrm{GeO}_{4}$ tetrahedra formed infinite random network [33]. Later, it was found that in binary alkali germanate glasses, some properties such as refractive index [34] and density [35] varied in an anomalous manner as a function of the alkali oxide content. This anomaly was interpreted to be the result of the change of Ge coordinated from 4 to 6 . This hypothesis was strengthened by infrared studies [36]. In the last few years, quantitative information has been obtained on this so-called germanate anomaly. Thus in 1979, Kamiya and Sakka [8] reported that from X-ray diffraction studies, the Ge coordination appeared to increase with increasing alkali as seen in Figure 2. Improvements in infrared

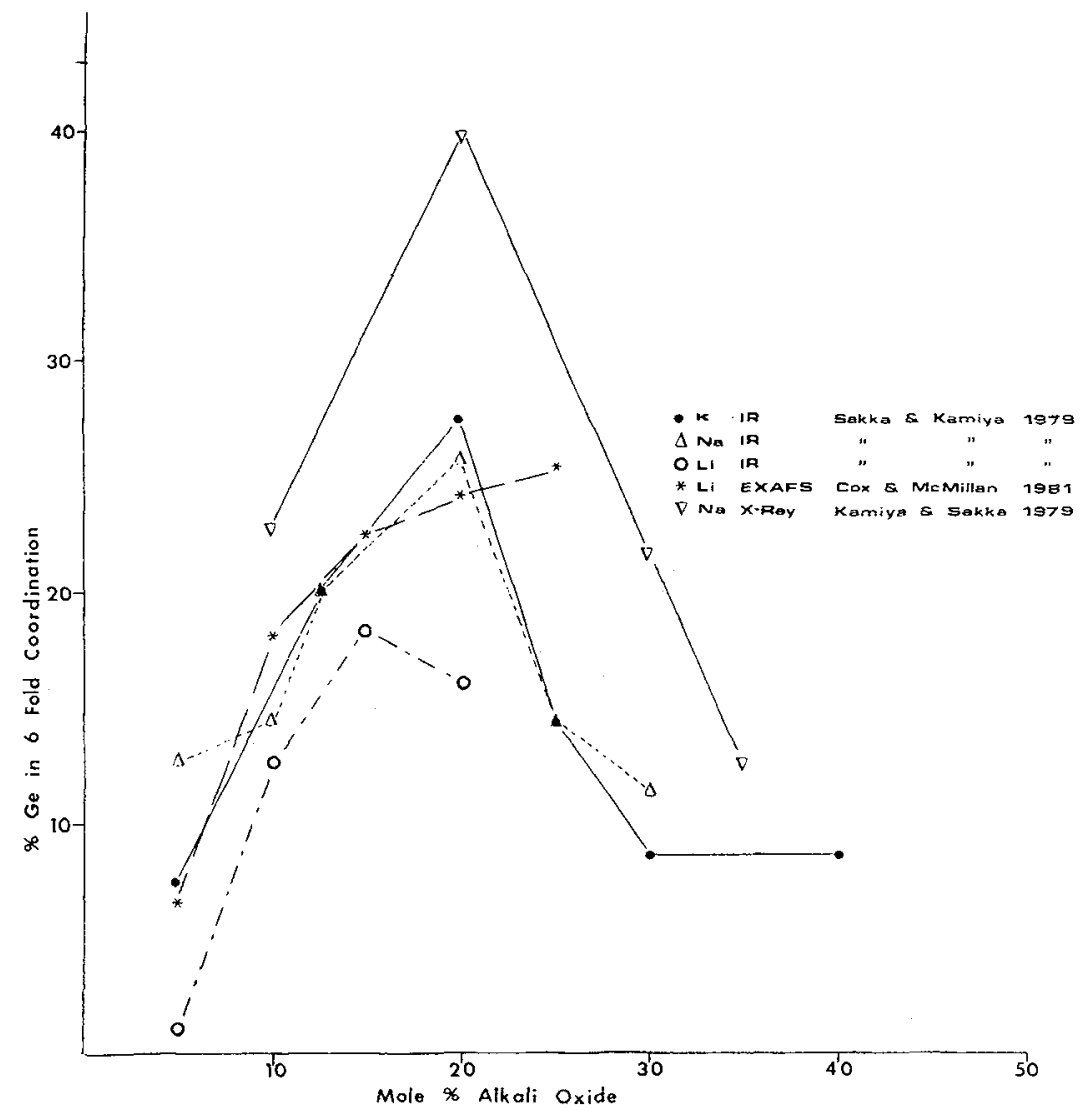

FIGURE 2. Variation of coordination number of Ge in binary alkali germanate techniques and comparison with the spectra of corresponding crystals [37] also led to the confirmation of the coordination chance (Finure 2). Studies of the Raman spectra of crystalline and glassy germanates pernitted Verweij and Buster to confirm the formation of $\mathrm{GeO}_{6}$ groups and to identify the number of non-bridging oxygens as a function of composition [38]. In 1981, Cox and McMillan reported that from EXAFS studies of 1 ithium germanates, the formation of $\mathrm{GeO}_{6}$ groups was further confirmed as shown in Figure 2 [5]. Although the results of IR, X-ray, and EXAFS are not in exact quantitative agreement, it can be concluded that significant 
progress has been made since 1979. The above-mentioned information is concerned primarily with short-range structure of course, and it is apparent that a great deal of research is still necessary. There is indication at least from a correlation of the Raman spectra of crystalline and glassy germanates that chains of Ge0 tetrahedra are apparently connected by $\mathrm{GeO}_{6}$ octahedra. in the glasses over certain composition ranges.

(b) Silicates and Phosphates: X-ray photoelectron spectroscopy (XPS) has been used to distinguish between bridging and non-bridging oxygens in silicates and phosphate glasses, mainly from the work of Brückner and co-workers [1]. The observed low energy 0 (15) line due to photoelectrons was attributed to non-bridging oxygens, $0_{n b}$, and the high energy line to bridging oxygens, $o_{b}$, in silicate glasses. The experimental data could be further treated by best-fit computer programs to obtain detailed information on the effects of cations on the two types of oxygens. In aluminosilicate glasses, the variation of the coordination number of AT from 6 to 4 could also be deduced from the chemical shifts of the 0 (1s) photoelectron band of $0_{n b}$ relative to that of $\mathrm{O}_{b}$ when the $\mathrm{Al}_{2} \mathrm{O}_{3} / \mathrm{Na}_{2} \mathrm{O}$ was varied $[1,4]$. The same technique was applied to phosphate glasses [2] to distinguish between $0_{n b}$ and $O_{b}$. By the use of a three-band best-fit program, Brückner and co-workers were able to identify even the doubly-bonded oxygens, $0_{d}$, in phosphates.

The coordination of $\mathrm{Ti}$ in a series of $\mathrm{TiO}_{2}-\mathrm{SiO}_{2}$ glasses has been studied by EXAFS and XANES [25]: Quantitative information was obtained regarding the relative abundance of $\mathrm{T} i$ in 6-fold and 4-fold coordinations. For instance, the concentration of 6 -fold $\mathrm{Ti}$ was estimated to vary from $5 \%$ at $7.5 \mathrm{wt} . \% \mathrm{TiO}_{2}$ to $18 \%$ at $9.5 \mathrm{wt} . \% \mathrm{TiO}_{2}$.

(c) $\mathrm{B}_{2} \mathrm{O}_{3}$ : The structures of boric oxide and borates are adequately dealt with by P. J.Bray in this conference. However, in the general context of this paper, it might be inquired if significant progress has been made recently with just $\mathrm{B}_{2} \mathrm{O}_{3}$. The structure of $\mathrm{B}_{2} \mathrm{O}_{3}$ glass had been the subject of many studies. Early work indicated that the boron atoms were three-coordinated and that the $\mathrm{BO}_{3}$ triangular groups formed extended random network. The existence of boroxol rings with three $\mathrm{Bo}_{3}$ triangles were first postulated in 1953 [39] and later supported by the work of Krogh-Moe [40]. In 1970, a new study of the structure of glassy $\mathrm{B}_{2} \mathrm{O}_{3}$ was undertaken by Mozzi and Warren [27] who concluded that randomly lined boroxol rings constituted a major part of the glass. In 1977, Bray and co-workers showed that from PIMR studies, some $80 \%$ of the borons were in boroxol rings [12]. More recent neutron diffraction studies, however, indicated that $60 \%$ of the borons were included in the boroxol rings [17]. Despite the discrepancy, it must be concluded that significant progress has been made on intermediate-range and long-range structural investigations al though the advances have been more evolutionary than revolutionary.

(d) $\mathrm{SiO}_{2}$ : Silica glass is probably the most investigated material among all disordered solids. Since 1930 , many models have been postulated. These range from the crystallite types to the random network types. The status up to 1969 has been summarized by Brückner. A new X-ray diffraction study was made by Mozzi and llarren in 1970 who confirmed the validity of the random network model [26]. In addition, these authors concluded that the Si-0-Si angle could vary all. the way from $120^{\circ}$ to $130^{\circ}$ with a maximum at $144^{\circ}$. Since 1970 , a great deal of modelling work has been performed and new results have been published based on neutron diffraction and Raman spectroscopy. Bell and Dean, for instance, suggested that in order to fit the measured X-ray and neutron correlation functions, a structural model must contain at least some 4-membered rings based on four $\mathrm{SiO}_{4}$ tetrahedra [42]. Others have suggested the existence of 6 -membered rings [43]. More recent neutron diffraction studies are consistent with the random network structure of the type suggested by Be11 and Dean [17]. Raman studies have led to the suggestions of 4-membered rings [4.4] as we11 as small amounts of 2 and 3-membered rings [18]. The proposed 
2-membered ring is particularly interesting in that the two adjacent silicons share 3 oxygens [18].

Recently, high-resolution electron microscopy (NREM) was used to investigate $\mathrm{SiO}_{2}$ glass [10]. Bright smal1 spots with sharp contrast were observed in the dark field image. The dark field images were compared with those calculated by a kinematical electron diffraction theory on the basis of random network and crystallite models. It was concluded that the observed bright spots were due to crystallites of approximately $17 \mathrm{~A}$ in dimensions. Bando and Ishizuka [10] thus concluded that the structure of silica glass agreed with the crystallite model proposed earlier by Porai-Koshits [45]. Although Bando and Ishizuka did not mention the concentration of these crystallites versus the interconnecting random network, the electron micrograph showed that the amount of bright spots were significant, apparently much more than $10 \%$. It thus appears at present that the structure of $\mathrm{SiO}_{2}$ glass is still a subject of controversy, despite the utilization of the best experimental tools and new theoretical calculations.

(e) Halides: Glasses based on beryllium fluoride were first reported by Goldschmidt over 40 years ago [46]. Warren and $\mathrm{Hill}_{1}$ studied the structure of $\mathrm{BeF}_{2}$ glass by $X$-ray diffraction in 1934 and concluded that BeF glass was structurally analogous to $\mathrm{SiO}_{2}$ glass with the $\mathrm{BeF}_{4}$ tetrahedra forming extended three-dimensional network [47]. Recent7y, Weber and co-workers have used laser-induced fluorescence line narrowing ( $F L N$ ) to study rare-earth doped BeF 2 glasses [11] and indicated that the rare-earth ions could have 5-, 6-, and 7-fold fluorine coordination. Perhaps the most stimulating results recently have come from the molecular dynamics simulations of the structure of these glasses by Brawer and Weber [29]. These results suggested that a significant number of the Be ions could be five-coordinated by fluorines.

For many years, $\mathrm{BeF}_{2}$-based glasses were the only known fluoride glasses. In 1975 , Poulain, Poulain, and Lucas reported the discovery of new fluoride glasses based on $\mathrm{ZrF}_{4}$. Since that time, numerous new fluoride glasses have been reported [49].

The structures of these new fluoride glasses are naturally subjects of much interest. It has been reported that the coordination of the $\mathrm{Zr}$ ions in these g7asses could vary from 6,7 and 8 [50-52]. There are already controversies between Raman spectroscopy and X-ray diffraction interpretations. Large coordination numbers for so-called network-forming jons in the fluorides were not expected from studies of oxides. Structural investigations of the new halide glasses will offer many new challenges in the future.

Another simple glass-forming hajide which has been the subject of many investigations is $\mathrm{ZnCl}_{2}$. Early work suggested that $\mathrm{ZnCl}_{4}$ tetrahedra are the principal building unit to give a three-dimensional random network similar to that for $\mathrm{SiO}_{2}[53-54]$. Recent EXAFS studies, however, suggested that the average coordination number of the $\mathrm{Zn}$ ion is $5.1+0.8$ which is significantly higher than the average value of four determined by X-ray diffraction [55]. The controversies could have been the result of the possible presence of water as an impurity in $\mathrm{ZnCl}_{2}$ glasses. Raman spectroscopy and inelastic neutron scattering studies made on carefully dehydrated $\mathrm{ZnCl}_{2}$ glass indicated $\mathrm{ZnCl}_{4}$ tetrahedra were the more likely units in a random network structure.

(f) $\mathrm{As}_{x}(\mathrm{~S}, \mathrm{Se}, \mathrm{Te})_{1-x}$ : Structural studies on arsenic chalcogenides up to the early 7960 's revealed that in $\mathrm{As}_{2} \mathrm{~S}_{3}$, the coordination numbers for $A$ s and $S$ are 3 and 2 respectively [57-59]. The As-S bond length was found to be $2.3 \mathrm{~A}$ and the $A s-S-A s$ and S-As-S angles to have a similar value of $99^{\circ}$. The structure proposed for $\mathrm{As}_{2} \mathrm{~S}_{3}$ glass was that of chains or layers. Al] subsequent investigations [60-64] confirmed the 2- and 3-coordinations. Later Leadbetter and Apling [61] 
proposed that bulk glassy $\mathrm{As}_{x} \mathrm{~S}_{(1-x)}$ and $\mathrm{As}_{x} \mathrm{Se}_{(1-x)}$ have structures involving extended sheets with As-S and AS-Se bond lengths of $2.24 \mathrm{~A}$ and $2.44 \mathrm{~A}$ respectiveiy. Later Apling, Leadbetter, and Wright found that the structure of vapor-deposited amorphous films of arsenic chalcogenides to be different from that of the bulk glasses [63]. A model consisting of a mixture of highly polymerized molecular species was found to fit the experimental data. Chang and Dove [60] have studied the structure of $\mathrm{As}_{2} \mathrm{Se}_{x} \mathrm{Te}_{(3-x)}$ and found that the short range order appeared to be similar for the amorphous and crystalline phases of $\mathrm{As}_{2} \mathrm{Se}_{3}$ but not for the $\mathrm{As}_{2} \mathrm{Te}_{3}$ phases. In a later study by Pettifer et a1. [62], using EXAFS, it was conciuded that glassy $\mathrm{As}_{2} \mathrm{Te}_{3}$ actually possessed a higher degree of order for nearest neighbors than the known crystal forms of $\mathrm{As}_{2} \mathrm{Te}_{3}$. The present conclusion for these chalcogenides is thus progress has been made in an evolutionary manner.

4. Conclusions. - Because of the extremely large amount of published information, onty a few examples have actually been given above. Based on our exhaustive evaluations, however, some general conclusions can be made. These are:

(a) Considerable progress has been made in both experimental and theoretical studies.

(b) Most of the work has been on short-range structures.

(c) Progress has been mostiy of a confirmatory nature and has been evolutionary rather than revolutionary.

(d) Strictly speaking, there has been realiy no "new" methods.

(e) A great deal of uncertainty and some controversies still exist for the simplest solids.

(f) Further progress is likely only through the utilization of more than one method.

(g) Correlation of structure with properties is still grossly lacking.

Acknowledgements. - We are grateful to the Directorate of Chemical and Atmospheric Sciences, Air Force Office of Scientific Research for support under Grant No. 80-0059. The advice and comments of C. A. Angell, Y. Bando, H. S. Chen, J. Finney, H. Fritzsche, F. L. Galeener, P. H. Gaskell, A. J. Leadbetter, F. W. Lytle, R. K. MacCrone, P. W. McMillan, J. C. Phillips, S. Sakka, J. F. Shackelford, M. J. Weber, R. A. Weeks, and A. C. Wright contributed significantly to this review.

\section{References}

11/ Bruckner, R., Chun, H., and Goretzki, H., Glastech. Bur. 51, 1 (1978).

12) Gresh, R., Müller-Warmuth, W., and Dutz, H., J. Non-Cryst. Solids 34 , $127(1979)$.

13/ Lam, D. J., Paulikas, A. P., and Veal, B. W., J. Non-Cryst. Solids 42 , $41(1980)$.

14) Smets, B. M. J. and Lommen, T. P. A., Phys. Chem. Glasses 22, 158 (1981).

15/ Cox, A.D. and McMillan, P.W., J. Non-Cryst. Solids 44, 257 (1981).

16) R. F. Pettifer, 4th EPS Gen. Conf. Trends in Physics, 522-532, Adam Hilger, Bristol, England (1979). 
17/ Sakka, S., Kamiya, K., and Hayashi, M., Bull. of Institute for Chem. Res. Kyoto Univ., 59, 172 (1981).

/8/ Kamiya, K. and Sakka, S., Phys. Chem. Glasses 20, 60 (1979).

19/ Lytle, F.W., Sayers, D.E., and Stern, E.A., Phys. Rev. B 11, 4825 (1975).

/10/ Bando, Y. and Ishizuka, K., J. Non-Cryst. Solids $\underline{33}, 375$ (1979).

111/Weber, M. J., in Laser Spectroscopy in Solids, ed. H. M. Yen and P. M. Selzer, Springer-Verleg, Berlin (1981).

/12/ Jellison, Jr., G. E., Panek, L.W., Bray, P. J. and Rouse, Jr., G. B., J. Chem. Phys. 66, 802 (1977).

113/ Bray, P. J., in Mat. Sci. Res., Vol. 12, ed. L. D. Pye, V. D. Frechette and N. J. Kreid7, 327-35i, Plenum, N.Y., (1978).

114/ Guglielmi, M. and Principi, G., J. Non-Cryst. Solids 48, 161 (1978).

/15/ Tenhover, M., J. Non-Cryst. Solids 44,85 (1981).

116/ Wright, A. C. and Leadbetter, A. J., Phys. Chem. Glasses 17, 122 (1976).

117/ Sinclair, R. N., Desa, J.A.E., Etherington, G., Johnson, P.A.V. and Wright, A.C., J. Non-Cryst. Solids $\underline{42}, 107$ (1980).

118/ Galeener, F. L., J. Non-Cryst. Solids $\underline{49}, 53$ (1982).

19/ Galeener, F. L. and Mikkelsen, Jr., J.C., Solid State Comm. 30, 505 (1979).

120/ Galeener, F. L., J. Non-Cryst. Solids 40,527 (1980).

121/ Bando, Y., Iijima, S., Kawamoto, Y., and Tomozawa, M., J. Non-Cryst. Solids 42,151 (1980).

122/ Bando, Y., I Ijima, S., Kawamoto, Y. and Tomozawa, M., J. Non-Cryst. Solids 43,279 (1981).

123/ Willjams, J.A., Rindone, G.E. and McKinstry, H.A., J. Am. Ceram. Soc. 64, $697(1981)$.

124/ Zarzycki, J., Proc. 10th Int. Congress on Glass, Kyoto 12, 28 (1974).

125/ Sandstrom, D.R., Lytle, F.W., Wei, P.S.P.,Greegor, R.B., Wong, J. and Schultz, P., J. Non-Cryst. Solids 41, 201 (1980).

126/ Mozzi, R. L. and Warren, B.E., J. Appi. Crystallogr. 2, 164 (1969).

127/ Mozzí, R. L. and Warren, B.E., J. Appl. Crystallogr. 3, 251 (1970).

128/ Wagner, C.N.J., J. Non-Cryst. Solids 42, 3 (1980).

129/ Brawer, S.A. and Weber, M. J., J. Chem. Phys. 75, 3522 (7981).

130/ Wright, A.C., Conne 11, G.A.N. and Allen, J.W., J. Non-Cryst. Solids 42, 69 (1980).

131/ Shackleford, J.F. and Brown, B.D., J. Non-Cryst. Solids 44, 379 (1981). 
132/ Shackleford, J. F., J. Non-Cryst. Solids 42, 165 (1980).

133/ Warren, B.E., Phys. Rev. 45, 657 (1934).

134/ Ivanov, A.0. and Evstropiev, K.S., Dokl. Akad Nauk SSSR, 145, 797 (1960).

/35/ Murthy, M.K. and Ip. J., Nature, Lond. 18, 285 (1964).

136/ Murthy, M. K. and Kirby, E.M., Phys. Chem. Glasses 5, 144 (1964).

/37/ Sakka, S. and Kamiya, K., Rev. Chim. Min. 16, 293 (1979).

138/Verweij, H. and Buster, J.H.J.M., J. Non-Cryst. Solids 34, 81 (1979).

/39/ Goubeau, J. and Keller, H. Z. anorg. Chem. 22, 303 (1953).

140/ Krogh-Moe, J., J. Non-Cryst. Solids I, 269 (1969).

141/ Brückner, R., J. Non-Cryst. Solids 5, 123 (1970).

142/ Be11, R. J. and Dean, P., Phi1. Mag. 25, 1381 (1972).

143/ Konnert, J. H., Ferguson, G. H., and Karle, J., Science 184, 93 (1974).

144/ Sharma, S. K., Mammone, J.F., and Nicol, M. F., Nature 292, 140 (1981).

145/ Porai-Koshits, E.A., Glastech. Ber. 32, 450 (1959).

146/ Goldschmidt, V. M., Skrifter Norske Vid. Akad. (Os10) $\underline{8}, 127$ (1926).

147\% Warren, B.E. and Hi11, C.F., Z. Krist. 89, 481 (1934).

148/ Poulain, M., Poulain, M., and Lucas, J., Mat. Res. Bu11. 10, 243 (1975).

/49/ Baldwin, C.M., A7meida, R. M. and Mackenzie, J.D., J. Non-Cryst. Solids 43, 309 (1981).

150/ Poulain, M., Chanthanasinh, M., and Lucas, J., Mat. Res. Bu11. 12, 151 (1977).

151/ Lucas, J., Chanthanasinh, M., Poulain, M., Poulain, M., Brun, P., and Weber, M. J., J. Non-Cryst. Solids 27, 273 (1978).

152) Aimeida, R. M. and Mackenzie, J.D., J. Chem. Phys. 74, 5954 (1981).

153/ Ange]1, C.A. and Wong, J., J. Chem. Phys. 53, 2053 (1970).

154/. Imaoka, M. Konagaya, Y., and Hasegawa, H., J. Ceram. Soc. Jap. 79, 97 (1971).

155/ Wong, J. and Lytie, F.W., J. Non-Cryst. Solids 37, 273 (1980).

156/ Galeener, F. L., Mikkelsen, J.C., Wright, A.C., Sinclair, R. N., Desa, J.A.E., and Wong, J., J. Non-Cryst. Solids 42, 23 (1980).

157/ Vaipolin, A.A. and Porai-Koshits, E.A., Sov. Phys. Solid State 2, 1500 (1960).

158/ Petz, J.I., Kruh, R.F., and Amstutz, G.C., J. Chem. Phys. 34, 526 (1961).

159/ Hopkins, T.E., Pasternak, R.A., Gould, E.S. and Herndon, J.R., J. Phys. Chem. 66, 733 (1962). 
160/ Chang, J. and Dove, D.B., J. Non-Cryst. Solids 16, 72 (1974).

161/ Leadbetter, A. J. and Apling, A. J., J. Non-Cryst. Solids 15, 250 (1974).

162/ Pettifer, R.F., McMillan, P.W., and Gurman, S.J., in The Structure of Non-Crystalline Materials, ed. by P. H. Gaske11, pp. 63-67, (Taylor and Francis, London, 1977).

163/ Apling, A. J., Leadbetter, A. J., and Wright, A.C., J. Non-Cryst. Solids $23,369(1977)$.

164/ Uemura, 0., Sagara, Y., Muno, D. and Satow, T., J. Non-Cryst. Solids 30, 355 (3978). 